\title{
Front Matter: Volume 10832
}

, "Front Matter: Volume 10832," Proc. SPIE 10832, Fifth Conference on Frontiers in Optical Imaging Technology and Applications, 1083201 (7 November 2018); doi: 10.1117/12.2515574

SDIE Event: Fifth Conference on Frontiers in Optical Imaging Technology and SPIE. Applications, 2018, Changchun, China 


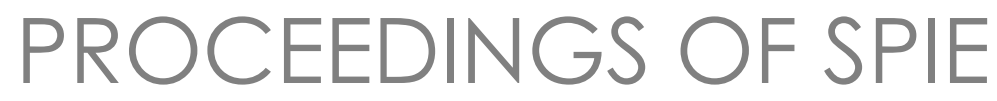

\title{
Fifth Conference on Frontiers in Optical Imaging Technology and Applications (FOI 2018)
}

\author{
Junhao Chu \\ Wenqing Liu \\ Huilin Jiang \\ Editors
}

25-27, July 2018

Hefei, China

Organized by

Chinese Society for Optical Engineering (China)

Photoelectronic Technology Committee, CSA (China)

The Key Laboratory of Polarization Imaging Detection Technology (China)

Sponsored by

Chinese Society for Optical Engineering (China)

Chinese Academy of Engineering (China)

National Natural Science Foundation of China (China)

Published by

SPIE 
The papers in this volume were part of the technical conference cited on the cover and title page. Papers were selected and subject to review by the editors and conference program committee. Some conference presentations may not be available for publication. Additional papers and presentation recordings may be available online in the SPIE Digital Library at SPIEDigitalLibrary.org.

The papers reflect the work and thoughts of the authors and are published herein as submitted. The publisher is not responsible for the validity of the information or for any outcomes resulting from reliance thereon.

Please use the following format to cite material from these proceedings:

Author(s), "Title of Paper," in Fifth Conference on Frontiers in Optical Imaging Technology and Applications (FOI 2018), edited by Junhao Chu, Wenqing Liu, Huilin Jiang, Proceedings of SPIE Vol. 10832

(SPIE, Bellingham, WA, 2018) Seven-digit Article CID Number.

ISSN: 0277-786X

ISSN: 1996-756X (electronic)

ISBN: 9781510622890

ISBN: 9781510622906 (electronic)

Published by

SPIE

P.O. Box 10, Bellingham, Washington 98227-0010 USA

Telephone +1 3606763290 (Pacific Time) · Fax +1 3606471445

SPIE.org

Copyright (c) 2018, Society of Photo-Optical Instrumentation Engineers.

Copying of material in this book for internal or personal use, or for the internal or personal use of specific clients, beyond the fair use provisions granted by the U.S. Copyright Law is authorized by SPIE subject to payment of copying fees. The Transactional Reporting Service base fee for this volume is $\$ 18.00$ per article (or portion thereof), which should be paid directly to the Copyright Clearance Center (CCC), 222 Rosewood Drive, Danvers, MA 01923. Payment may also be made electronically through CCC Online at copyright.com. Other copying for republication, resale, advertising or promotion, or any form of systematic or multiple reproduction of any material in this book is prohibited except with permission in writing from the publisher. The CCC fee code is 0277 $786 \mathrm{X} / 18 / \$ 18.00$.

Printed in the United States of America.

Publication of record for individual papers is online in the SPIE Digital Library.

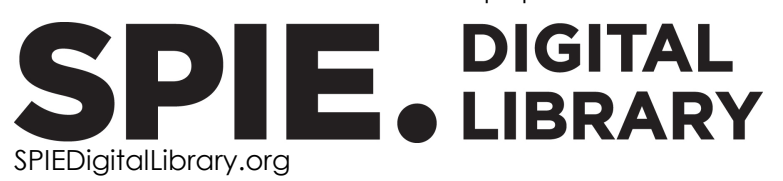

Paper Numbering: Proceedings of SPIE follow an e-First publication model. A unique citation identifier (CID) number is assigned to each article at the time of publication. Utilization of CIDs allows articles to be fully citable as soon as they are published online, and connects the same identifier to all online and print versions of the publication. SPIE uses a seven-digit CID article numbering system structured as follows:

- The first five digits correspond to the SPIE volume number.

- The last two digits indicate publication order within the volume using a Base 36 numbering system employing both numerals and letters. These two-number sets start with $00,01,02,03,04$, 05, 06, 07, 08, 09, OA, OB ... 0Z, followed by 10-1Z, 20-2Z, etc. The CID Number appears on each page of the manuscript. 


\title{
Contents
}

\author{
vii Authors \\ xi Conference Committee \\ xiii Introduction
}

FIFTH CONFERENCE ON FRONTIERS IN OPTICAL IMAGING TECHNOLOGY AND APPLICATIONS

$1083202 \quad$ An adaptive restoration method for motion-blurred image based on Wiener filtering [10832-1]

1083203 High quality coherent imaging of the object behind the scattering media with one accurate power spectrum pattern [10832-3]

1083204 A scheme to realize super-resolution by push-broom compressive sampling multi-spectral image system [10832-4]

1083205 Test for dynamic range of scientific CCD imaging system [10832-5]

1083206 Research on SIFT polarization image registration method based on matching optimization [10832-6]

$1083207 \quad$ Neural network non-uniformity correction for eliminating low frequency noise [10832-7]

1083208 Research of infrared digital camouflage design and generation [10832-8]

1083209 Multi fields application of wide-band imaging spectrometer data of Tiangong-2 Space Laboratory [10832-9]

10832 OA Distribution characteristics of lower troposphere atmospheric $\mathrm{CO}_{2}$ in Hefei Science Island [10832-11]

$10832 \mathrm{OB} \quad$ Extending the depth-of-field and ranging the scene with a shifted phase mask [10832-12]

10832 OC Retrieving atmospheric water vapor content based on absolute brightness of sky background spectral radiation [10832-13]

10832 OD Design of compact freeform off-axis TMA system [10832-14]

10832 OE Generating stereoscopic videos of realistic 3D scenes with ray tracing [10832-15] 
10832 OF The experiment analysis of LWIR thermal camera's imaging under the influence of integrate time [10832-16]

10832 OG High efficient linearly polarized light emission from InGaN/GaN LED with patterned nanostructures [10832-17]

$10832 \mathrm{OH} \quad$ Single-band spectral light field images reconstruction based on compressed sensing [10832-18]

$10832 \mathrm{Ol} \quad$ Low altitude polarization hyperspectral target detection based on CNN method [10832-19]

$10832 \mathrm{~J} \quad$ External cavity quantum cascade laser based gas sensor for chemical detection [10832-20]

10832 OK Super-resolution imaging in thick scattering samples by structured illumination microscopy with dual nonlinear effects [10832-21]

$10832 \mathrm{OL} \quad$ Influence of femtosecond laser pulse width on performance of terahertz time domain spectrometer [10832-22]

10832 OM Implementation of pupil location system based on bright pupil effect [10832-23]

10832 ON Distance-weighted modulation transfer function measurement method [10832-24]

1083200 The numerical analysis and application of camouflage target DOLP under low illumination [10832-25]

10832 OP Rotorcraft UAV laser charging target center location algorithm [10832-26]

$108320 Q \quad$ Simulation of laser ranging system for LEO non-cooperative targets based on Monte Carlo method [10832-29]

10832 OR Bone organ printing based on surface structure light projection 3D contour measurement [10832-30]

10832 OS A none-blind deblurring algorithm for noisy images via distributed gradient prior [10832-32]

10832 OT The study of multi-beam interference effect [10832-33]

$10832 \mathrm{OU} \quad$ Image denoising algorithm based on adversarial learning using joint loss function [10832-34]

10832 OV Research on measurement method of characteristics infrared small light points beam [10832-35]

10832 OX Blind tone-mapped image quality assessment based on clustering perception [10832-37]

10832 OY A survey of detector technology in laser ranging system [10832-38]

$108320 Z \quad$ Rotary infrared tomography system design [10832-39] 
$1083210 \quad$ Reprojection-based method for camera arrays of refocusing onto arbitrary focal surfaces [10832-40]

$1083211 \quad$ Polarization analysis and correction for space-borne grating spectrometers [10832-41]

1083212 Study on the temporal and spatial distribution of atmospheric $\mathrm{SO}_{2}$ and $\mathrm{NO}_{2}$ in $\mathrm{Huainan}$ observed by Lidar [10832-44]

1083213 Design of a mid-wavelength infrared optical system based on high frame rate measuring [10832-45]

$1083214 \quad$ Long wave infrared optical system design based on fast and small target detection [10832-46]

$1083215 \quad$ Single image enhancement using dual boundaries [10832-47]

1083216 Study on the echo of the optical imaging system under different extent of damage to CCD [10832-48]

1083217 Infrared and visible image fusion method based on saliency detection and targetenhancement [10832-49]

$1083218 \quad$ Microscopic imaging improvement combining gradient constraint model and multi-fields of view analysis [10832-50]

1083219 Cascaded constant modulus equalization algorithm in wireless optical communication systems [10832-51]

10832 lA Wavelet-based approach for the fusion of low-light image pairs [10832-52]

10832 1B Fast r0 estimation for atmosphere turbulence via structural function [10832-53]

10832 1C Polarization characteristics of full-field and full-pupil in refraction and reflection telephoto system [10832-55]

10832 1D Baseline correction method for Raman spectra based on piecewise polynomial fitting [10832-58]

10832 1E Infrared radiation characteristics of solid rocket engine plume at high altitude [10832-63]

10832 IF Design and simulation of first-photon 3D lidar [10832-66]

10832 1G Uncertainty of measurement for testing sensitivity of low light level image intensifier [10832-68]

$10832 \mathrm{lH} \quad$ Design of a semi-active laser/active radar/infrared common aperture compound optical system [10832-73]

$1083211 \quad$ Research on ghost image reconstruction algorithm based on photons simulation with doubly Poisson stochastic process [10832-74] 
$108321 \mathrm{~J} \quad$ Numerical simulation of infrared spectrum and radiance characteristics of rocket engine exhaust plume [10832-75]

$10832 \mathrm{lK}$ Characterization and detection of spectral polarization information for ballistic target recognition [10832-79]

10832 IL Extinction ratio of the Glan-Taylor prism with deviated optical axes [10832-80]

$108321 \mathrm{M}$ Study on the applications of space-based polarization detection technique [10832-81]

$108321 \mathrm{~N} \quad$ Multi-touching imaging via sparse sensing [10832-82]

1083210 The technology of multi-mode tracking algorithm fusion decision based on background complexity perception [10832-83]

$10832 \mathrm{lP}$ The analysis of radiometric calibration based on long-wave infrared hyperspectral imaging spectrometer [10832-84]

10832 1Q Background radiation response evaluation of InGaAs detectors [10832-85]

10832 IR Design and simulation of single-photon three-dimensional compressive imaging system based on TCSPC [10832-86]

10832 is Research on real-time NUC method of infrared TDI detector based on bi-directional scanningimaging mechanism [10832-87]

10832 iT Low-light image enhancement based on joint convolutional sparse representation [10832-88]

$108321 \mathrm{U}$ Vision method of vehicle localization based on the roadside landmark [10832-94]

10832 IV Snapshot diffractive computational imaging spectroscopy [10832-95]

10832 1W Imaging detection system based on optical fiber faceplate coupling [10832-96]

10832 1X Impact of observation angle and radiance on LWIR polarimetric images [10832-97]

10832 IY High resolution perspective views extraction based on light field imaging theory [10832-98]

$1083212 \quad$ Advances and prospects of thin film phosphor for high resolution field emission displays [10832-99]

1083220 Study on the quality of jujube in Southern Xinjiang with hyperspectral near-surface remote sensing [10832-101]

1083221 Design of infrared APD detector for lidar [10832-102] 


\section{Authors}

Numbers in the index correspond to the last two digits of the seven-digit citation identifier (CID) article numbering system used in Proceedings of SPIE. The first five digits reflect the volume number. Base 36 numbering is employed for the last two digits and indicates the order of articles within the volume. Numbers start with 00, 01, 02, 03, 04, 05, 06, 07, 08, 09, OA, OB...0Z, followed by 10-1Z, 20-2Z, etc.

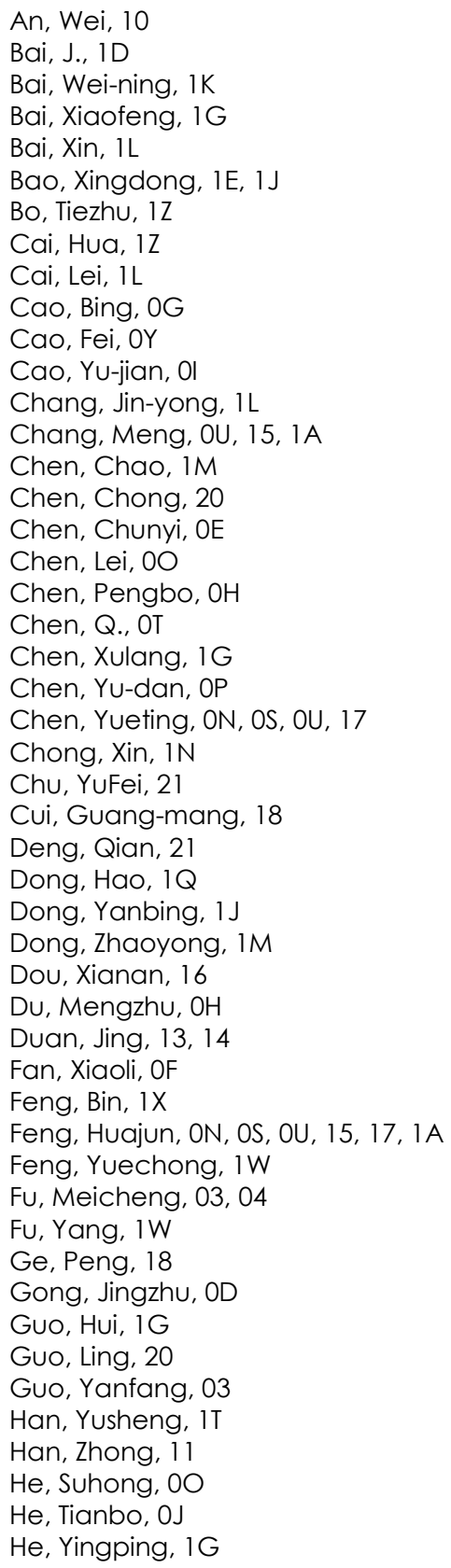

He, Yulan, OD

Hong, Jin, 1Q

$\mathrm{Hu}$, Feng, $\mathrm{OZ}$

Hu, H.B., 1D

$\mathrm{Hu}, \mathrm{Jie}, 08$

Hu, Qiuping, 10

$\mathrm{Hu}$, Shunxing, 0A, 12

$\mathrm{Hu}$, Xiande, 02

$\mathrm{Hu}$, Xian-zhe, $1 \mathrm{~L}$

$\mathrm{Hu}$, Xiao-li, $1 \mathrm{~K}$

Hua, Wei-ping, 18

Huang, Jian, OA, 12

Huang, Jiazi, OS

Huang, Kangsheng, $1 Z$

Huang, Wujun, IG

Huang, Yanhua, 00

Jia, Jinsheng, $1 \mathrm{~W}$

Jia, Nan, 05

Jia, Wenwu, 10

Jia, Yizhen, $\mathrm{OZ}$

Jiang Bie Ke, OR

Jiang, Gangyi, OX

Jiang, $\mathrm{HaO}, \mathrm{OX}$

Jiang, Kai, 13, 14

Jiang, Shurong, OK

Jiang, Zengbo, 10

Jiao, Jianchao, $1 \mathrm{~V}$

Jin, Xin, OG

Kang, Wenli, OD

Kong, Xianglong, $1 \mathrm{M}$

Kuang, ZhiQiang, 21

Lei, Hao, OF

Lei, Zhenggang, IP

$\mathrm{Li}$, Baosheng, $\mathrm{OZ}$

Li, Dan, 1F, 1I, IR

Li, Guo-chao, OL, OV

Li, H., OT

Li, Hui, IY

Li, Jianxin, IV

$\mathrm{Li}$, Jingsong, OJ

$\mathrm{Li}$, Junwei, $1 \mathrm{H}$

Li, Leijuan, 09

Li, Lingxiao, 17

Li, Mengzhu, 03, 04

Li, OU, OR

Li, Qi, ON, OS, OU, 15, 17, 1A

Li, Qian, 07

Li, Qingru, OK

$\mathrm{Li}$, Shengyang, 09 
Li, Song, OQ

$\mathrm{Li}$, Ting, $1 \mathrm{H}$

Li, Xilong, $1 \mathrm{~N}$

Li, Xiujian, 03, 04

Li, Yan, OD

Li, Yingchao, $1 \mathrm{C}$

Li, Yuan, OD

Liang, Shaolin, 05

Liang, Weidong, $\mathrm{OE}$

Lin, YU, OG

Liu, Chang, OF

Liv, Chuanming, 07

Liu, Dong, 21

Liu, Fan, OK

Liu, HaiZheng, $1 \mathrm{X}$

Liv, Hong-yuan, OL, OV

Liu, Hui, $1 \mathrm{Z}$

Liu, Hui-Qiang, OR

Liu, Kai, 13, 14

Liu, Kang, 09

Liu, Lidong, 07

Liu, Linlin, 12

Liu, Rui, $0 Q$

Liv, Xiaomin, $\mathrm{OH}$

Liu, Yanli, IV

Liu, Yunbiao, OE

Liu, Yunfei, 09

Liu, Zhaohui, OB

Liu, Zhenghai, 1Q

Liu, Zhi, 19

Long, Chao, $1 \mathrm{~L}$

LU, Qiang, 1B

Lu, Yuan, 08

Luan, Ze-Ming, OR

Luo, Huaping, 20

LV, Qiming, OJ

Ma, Feng, IS

Ma, Hualin, OX

Ma, Xiao, OC

$M a, Y ., 1 D$

Ma, Yue, $O Q$

Ma, Zhibang, $\mathrm{OH}$

Mao, Hongxia, 1E, $1 \mathrm{~J}$

Mao, Jinghua, 05

Mei, Haiping, OC

Meng, Ce, 19

Meng, Qingyun, 1G

$\mathrm{Mu}$, Lingli, 09

$\mathrm{Ni}$, Xiaolong, 19

Nie, Jinsong, 16

Nie, Qianwen, 03, 04

Peng, Jing, $1 Y$

Qi, Lin, OY

$\mathrm{Qi}, \mathrm{Xin}, \mathrm{OH}$

Qian, Kun, 1H

Qin, Bangyong, 09

Quan, Jing, $0 Z$

Ran, Jian, OY

Rao, Ruizhong, OC

Ren, G., OT
Rong, Xiao-long, $1 \mathrm{~K}$

Shan, Qiusha, OB, 13, 14

She, Wenji, OB

Shi, Entao, 05

Shi, Haodong, IC

Shi, ZeLin, $1 \mathrm{X}$

Song, Runsheng, 06

Song, Xinbo, 17, 1A

Su, Bida, OF

Su, Junbo, 07

Su, Yun, $1 \mathrm{~V}$

Sun, $\mathrm{Ke}, 16$

Sun, Peiyu, OA

Sun, Quansen, $1 \mathrm{~V}$

Sun, Quan-she, 11

Sun, Yong, $1 Z$

Tang, Shuai, is

Tang, Wusheng, 03, 04

Tang, Zili, 10

Tao, Huirong, OM

Tao, Ling, 11

Tian, Jinge, 03, 04

Wang, Chen, 12

Wang, Chinhua, OG

Wang, Feng, 06

Wang, Guangxia, 15, $1 \mathrm{~A}$

Wang, Hong-chao, OL, OV

Wang, Jianfeng, OG

Wang, Jiayu, $1 \mathrm{C}$

Wang, Jing, OF

Wang, Jiuwang, 1W, $1 \mathrm{Z}$

Wang, Kun, OR

Wang, Lei, 04

Wang, Miao, 0G, 14

Wang, Nanxi, OD

Wang, Ping, 03, 04

Wang, Qiancheng, $\mathrm{OH}$

Wang, Shao-shui, 11

Wang, Wei, 03

Wang, Xiaodong, 07

Wang, Xing-shu, $1 \mathrm{U}$

Wang, Y., OT

Wang, Yanhui, OK Wang, Yifan, 1F, 1I, 1R

Wang, Yingqian, 10

Wang, YinJian, 21

Wang, Yi-xue, $1 \mathrm{U}$

Wang, Yongmei, 05

Wang, Yun, IW

Wang, Ze-hong, OV

Wang, Zhenghua, $1 \mathrm{~J}$

Wang, Zhenhua, 1E

Wang, Zhiqiang, $1 \mathrm{~F}$

Wu, Bin, OL, OV

Wu, Chengguo, 00

Wu, Dong-sheng, OP

Wu, Hai-Ying, $1 \mathrm{~K}$

Wu, Shun-Hua, OR

WU, Yiqiang, $1 R$

Xia, Fei, 1P 
Xia, G., 1D

Xia, Zongze, $1 \mathrm{P}$

Xiao, Chao, 10

Xie, ChenBo, 21

Xie, Yuntao, 16

$X u$, Guoming, 02, 06, 0l

$\mathrm{Xu}, \mathrm{Ke}, \mathrm{OG}$

$X u$, Meng-en, 0 I

$X U$, Yanglei, $1 Z$

$X U$, Ying, OF, $1 \mathrm{~J}$

$X U, Z$ Zhi-guang, $1 U$

$X U$, Zhihai, ON, OS, OU, 15, 17, 1A

Xue, Mogen, $1 T$

Xue, Xinsong, 19

Yan, Peipei, 13, 14

Yan, Qiurong, 1F, 1I, 1R

Yang, Bo, 07

Yang, Chaozhi, OE

Yang, Hailong, $1 M$

Yang, Huamin, OE

Yang, Jie, OA, 12

Yang, Jungang, 10

Yang, Senlin, IN

Yang, Shuning, $1 \mathrm{G}$

Yang, Xing, 08

Yang, Yan-zhao, OL

Yang, Yibing, 1F, 1I, 1R

Yang, Zhi-xiong, IP

Yao, Haifeng, 19

Yi, Wenjun, 03, 04

Yin, Guoping, 15

Yin, Kaixin, 12

Ying, Cheng-ping, OV

Ying, Jia-ju, OP

Yu, Mei, OX

Yu, Chunchao, IP

Yu, Jing, OJ

Yu, Yongyi, OU

Yuan, Hongwu, 06

Yuan, Ke'e, OA, 12

Zeng, Haomin, $0 Q$

Zhang, Chengwen, 03

Zhang, Han, OK

Zhang, Jiang, 18

Zhang, Jie, $1 T$

Zhang, Li-Xia, OR

Zhang, Mengzi, 02

Zhang, Mingxin, 16

Zhang, Quan, OM

Zhang, San-Xi, IK

Zhang, W.D., ID

Zhang, Wenhao, $O Q$

Zhang, Xian, IW

Zhang, Xing, OY

Zhang, Xue-Liang, OR

Zhang, Yanhou, IT

Zhang, Yao-kai, $1 \mathrm{~L}$

Zhang, Yazhou, OF

Zhang, ZhanYe, 21

Zhang, Zheng, ON
Zhang, Zhiyu, OQ

Zhao, Fa-cai, 11

Zhao, Haibo, $1 \mathrm{~V}$

Zhao, Ju-feng, 18

Zhao, Ran, IW

Zhao, Xiao, $1 \mathrm{M}$

Zhao, YaoHong, IX

Zhao, Ying-wei, $1 \mathrm{U}$

Zheng, Wei-jian, IP

Zheng, Xiang-liang, 11

Zhou, Bing, OP

Zhou, Dongzhan, 1 Z

Zhou, Liang, OB

Zhou, Pucheng, $1 \mathrm{~T}$

Zhou, Taofei, $0 G$

Zhou, X., OT

Zhou, Yuanyuan, 10

Zhou, Zhuang, 09

Zhu, Mengjun, 03, 04

Zhu, R., OT

Zhu, Shasha, IM

Zhu, Yunfei, $\mathrm{OH}$

Zou, Peng, 1Q 
Proc. of SPIE Vol. 10832 1083201-10 Downloaded From: https://www.spiedigitallibrary.org/conference-proceedings-of-spie on 26 Apr 2023
Terms of Use: https://www.spiedigitallibrary.org/terms-of-use 


\title{
Conference Committee
}

\author{
Conference Chairs
}

Junhao Chu, Shanghai Institute of Technical Physics of the Chinese Academy of Sciences (China)

Wenqing Liu, Anhui Institute of Optics and Fine Mechanics, Chinese Academy of Sciences (China)

Huilin Jiang, Changchun University of Science and Technology (China)

Program Committee Chairs

Weiqi Jin, Beijing Institute of Technology (China)

Jin Lu, Tianjin Jinhang Institute of Technical Physics (China)

Shensheng Han, Shanghai Institute of Optics and Fine Mechanics (China)

Program Committee Co-chairs

Yadong Jiang, University of Electronic Science and Technology of China (China)

Guangcan Liu, Nanjing University of Information Science and Technology (China) 
Proc. of SPIE Vol. 10832 1083201-12 Downloaded From: https://www.spiedigitallibrary.org/conference-proceedings-of-spie on 26 Apr 2023
Terms of Use: https://www.spiedigitallibrary.org/terms-of-use 


\section{Introduction}

We had the great honor of organizing The Fifth Conference on Frontiers in Optical Imaging Technology and Applications (FOI 2018). It was a great pleasure for us to greet more than 300 participants from the many different countries who attended. We firmly believe this conference will become an important international event in the field of optical imaging technology.

The Fifth Conference on Frontiers in Optical Imaging Technology and Applications (FOI 2018) was sponsored by the Chinese Society for Optical Engineering, Chinese Academy of Engineering, and National Natural Science Foundation of China, and was organized by the Chinese Society for Optical Engineering, Photoelectronic Technology Committee, CSA, (China) and the Key Laboratory of Polarization Imaging Detection Technology (China).

The purpose of this conference is to provide a forum for the participants to report and review innovative ideas and up-to-date progress and developments and discuss novel approaches to applications in the optical imaging field. It is sincerely hoped that, as a result, research and development in optical imaging field will be promoted, and international cooperation will be enhanced.

On behalf of the other Co-chairmen, and the Organization Committee, I would like to heartily thank our sponsors and cooperating organizers for all they have done for the conference. Thanks also to all the authors for their contributions to the proceedings, to all of the participants and friends for their interests and effort in helping us to make the conference possible, to the Program Committee for its effective work and valuable advice, especially the Secretariat, and to SPIE staff for their tireless efforts and outstanding service in preparing and publishing the proceedings.

Junhao Chu 
Proc. of SPIE Vol. 10832 1083201-14 Downloaded From: https://www.spiedigitallibrary.org/conference-proceedings-of-spie on 26 Apr 2023
Terms of Use: https://www.spiedigitallibrary.org/terms-of-use 